\title{
EL DISCERNIMIENTO: DE LA ESPIRITUALIDAD A LA ÉTICA
}

\author{
Discernment: From Spirituality to Ethics
}

Tony Mifsud S.J.'

\section{Resumen}

El tema del discernimiento se ha reducido al campo de la espiritualidad con una clara referencia a la vida religiosa y sacerdotal. Sin embargo, en san Pablo tiene una innegable aplicación ética, relacionada con la vocación cristiana en general. Por otra parte, la espiritualidad es la base y fundamento del ethos cristiano. Por tanto, el tema del discernimiento constituye un puente entre la espiritualidad y el ethos cristiano, capaz de erigirse como un método de llegar a juicios éticos concretos. Tradicionalmente, en la Teología Moral se recurría a dos métodos: la deontología (la aplicación de la norma a la realidad) y la teleología (la finalidad determina la eticidad del acto). El artículo propone un tercer método: el discernimiento ético, que presupone una consecuencia y una coherencia entre la fe profesada y la vivencia cotidiana. El artículo comienza con un estudio del término discernimiento en el pensamiento teológico de san Pablo, para pasar luego a las reglas de discernimiento en los Ejercicios Espirituales de san Ignacio de Loyola y terminar con una comprensión más acabada de su significado en las reflexiones del Papa Francisco. Después de aclarar el significado del término discernimiento queda manifiesto que esta categoría constituye un puente sólido entre la espiritualidad y la ética, siendo un método para traducir la vivencia espiritual en un compromiso ético. Se termina con la propuesta de un método concreto para la formación de un juicio ético.

Palabras clave: Discreción de Espíritus; Discernimiento; Espiritualidad Ignaciana; Reglas de Discernimiento; Ética; Consolación; Desolación; Teleología; Deontología; Teología Paulina.

1 Doctor en Teología Moral por la Universidad Pontificia de Comillas, España. Profesor del departamento de Teología, Universidad Católica del Norte, Antofagasta, Chile. Correo electrónico: tmifsudsj@gmail.com 


\section{Abstract}

The theme of discernment has been reduced to the field of spirituality with a clear reference to religious and priestly life. However, in Saint Paul it has an undeniable ethical application, linked to the Christian vocation in general. On the other hand, spirituality is the base and foundation of the Christian ethos. Therefore, the theme of discernment constitutes a bridge between spirituality and the Christian ethos, capable of establishing itself as a method of reaching concrete ethical judgments. Traditionally, in Moral Theology, two methods were applied: deontology (the application of the norm to reality) and teleology (the purpose determines the ethics of the act). The article proposes a third method: ethical discernment that presupposes a consequence and a coherence between professed faith and daily living. The article begins with a study of the term discernment in the theological thought of Saint Paul, then moves on to the rules of discernment in the Spiritual Exercises of Saint Ignatius of Loyola and ends with a more complete understanding of its meaning in the reflections of Pope Francis. Once the meaning of the term discernment is elucidated, it becomes clear that this term constitutes a solid bridge between spirituality and ethics, being a method of converting the spiritual experience into an ethical commitment. It ends with the proposal of a concrete method for the formation of an ethical judgment.

Keywords: Discretion of Spirits; Discernment; Ignatian Spirituality; Rules of Discernment; Ethics; Consolation; Desolation; Teleology; Deontology; Pauline Theology.

\section{Introducción}

En el ejercicio del discernimiento, escribe Juan Pablo II, se intenta reconocer "una llamada que Dios hace oír en una situación histórica determinada; en ella y por medio de ella Dios llama al creyente" (Juan Pablo II, 1992, no. 10). Por consiguiente, escribe el Papa Francisco, el pensamiento cristiano:

Nunca se encierra, nunca se repliega en sus seguridades, nunca opta por la rigidez autodefensiva... sabe que él mismo tiene que crecer en la comprensión del Evangelio y en el discernimiento de los senderos del Espíritu, y entonces no renuncia al bien posible, aunque corra el riesgo de mancharse con el barro del camino. (Francisco, 2013, no. 45).

\section{1.- EL DISCERNIMIENTO EN EL PENSAMIENTO TEOLÓGICO}

En la actualidad, la palabra discernimiento ha superado dos límites que la tenían reducida a la sola disciplina de la espiritualidad y con el significado preciso de su dimensión para la vida religiosa. Discernir la vocación se entendía, unilateralmente, como una elección a la vida religiosa o al sacerdocio. El Concilio Vaticano II rompió esta estrechez de miras y la incluyó en el concepto eclesiológico de la sinodalidad de la Iglesia.

Así, Juan Pablo II, en Christifedelis laici, recuerda que el Concilio superó interpretaciones precedentes y prevalentemente negativas, abriéndose a una visión decididamente positiva, manifestando: 
La plena pertenencia de los fieles laicos a la Iglesia y a su misterio, y el carácter peculiar de su vocación, que tiene en modo especial la finalidad de buscar el Reino de Dios tratando las realidades temporales y ordenándolas según Dios”. (Juan Pablo II, 1988)

Así:

Con el nombre de laicos - así los describe la Constitución Lumen gentium - se designan aquí todos los fieles cristianos a excepción de los miembros del orden sagrado y los del estado religioso sancionado por la Iglesia; es decir, los fieles que, en cuanto incorporados a Cristo por el Bautismo, integrados al Pueblo de Dios y hechos partícipes a su modo del oficio sacerdotal, profético y real de Cristo, ejercen en la Iglesia y en el mundo la misión de todo el pueblo cristiano en la parte que a ellos les corresponde". (Juan Pablo II, 1988, no. 9)

Así, por el bautismo, existe una común vocación que no permite distinguir entre superiores e inferiores.

"Todos en la Iglesia, precisamente por ser miembros de ella, reciben y, por tanto, comparten la común vocación a la santidad. Los fieles laicos están llamados, a pleno título, a esta común vocación, sin ninguna diferencia respecto de los demás miembros de la Iglesia” (Juan Pablo II, 1988, no. 15).

Es decir:

Llamados a vivir la plenitud de la vida cristiana y a la perfección de la caridad... La vida según el Espíritu, cuyo fruto es la santificación" (cf. Rom 6, 22; Gal 5, 22), suscita y exige de todos y de cada uno de los bautizados el seguimiento y la imitación de Jesucristo, en la recepción de sus Bienaventuranzas, en el escuchar y meditar la Palabra de Dios, en la participación consciente y activa en la vida litúrgica y sacramental de la Iglesia, en la oración individual, familiar y comunitaria, en el hambre y sed de justicia, en el llevar a la práctica el mandamiento del amor en todas las circunstancias de la vida y en el servicio a los hermanos, especialmente si se trata de los más pequeños, de los pobres y de los que sufren. (Juan Pablo II, 1988, no. 16)

En otras palabras, hay una igual dignidad entre todos los miembros de la Iglesia por obra del sacramento del bautismo, pero una distinción en cuanto a la vocación específica. Hay una unidad en la diferencia o complementariedad en la diversidad. Es el concepto paulino del Cuerpo Místico de Cristo.

La comunión eclesial se configura, más precisamente, como comunión orgánica, análoga a la de un cuerpo vivo y operante. En efecto, está caracterizada por la simultánea presencia de la diversidad y de la complementariedad de las vocaciones y condiciones de vida, de los ministerios, de los carismas y de las responsabilidades. Gracias a esta diversidad y complementariedad, cada fiel laico se encuentra en relación con todo el cuerpo y le ofrece su propia aportación. (Juan Pablo II, 1988, no. 20)

La palabra vocación puede entenderse, en el sentido amplio, como un llamado de Dios (Francisco, 2019, no. 248). Con respecto a la vocación, Francisco comienza resaltando su carácter universal. Dos coordenadas determinan la vocación del cristiano: el llamado a la amistad con Jesús y el llamado a ser para los demás. El Papa constata que, para la enorme mayoría de los cristianos, la vocación se traducirá en la vida familiar y en su trabajo: la propuesta es entonces una espiritualidad que permita vivir ambas 
dimensiones como llamados de Dios... En definitiva, la propuesta de Francisco es que todo cristiano puede vivir su vida como vocación... En este sentido, es valorable la normalización del concepto de vocación: es el modo en que todo cristiano puede entender su vida, como expresión de su relación con Jesús y de su servicio a los demás (Rojas, 2019, p. 39).

Si la vida del cristiano se comprende desde la vocación, entonces el discernimiento resulta fundamental y fundante para su vida, ya que el discernimiento es el camino para descubrir la propia vocación. "Una expresión del discernimiento es el empeño por reconocer la propia vocación” (Francisco, 2019, no. 283).

Este discernimiento no se limita a un ejercicio de la razón,

Porque se trata de entrever el misterio del proyecto único e irrepetible que Dios tiene para cada uno... Está en juego el sentido de mi vida ante el Padre que me conoce y me ama, el verdadero para qué de mi existencia que nadie conoce mejor que Él” (Francisco, 2019, no. 280).

Por tanto, implica dejarse transformar por Cristo, reconociendo:

la obra de Dios en la propia experiencia cotidiana, en los acontecimientos de la historia y de las culturas de las que formamos parte, en el testimonio de tantos hombres y mujeres que nos han precedido o que nos acompañan con su sabiduría. (Francisco, 2019, no. 282)

Mchas veces y de muchas maneras habló Dios en el pasado a nuestros Padres por medio de los Profetas. En estos últimos tiempos nos ha hablado por medio del Hijo, a quien instituyó heredero de todo y por quien también hizo el universo. (Heb 1, 1-2).

Estas palabras de la Escritura fundamentan la necesidad de discernir la voz de Dios en la historia o, en términos conciliares, la lectura de los signos de los tiempos. El punto central es la persona de Jesús. Jesús no es un profeta sino el profeta. Él envía al Espíritu para que habla en nosotros. Por tanto, cabe al cristiano discernir esta voz del Espíritu.

La expresión discernimiento de espiritus se encuentra en las cartas del Nuevo Testamento (Cf. 1 Cor 12, 10; $1 \mathrm{Jn} 4,1$ ), pero no en los Evangelios. Estos traen, sin embargo, la experiencia vivida de discernimiento. Los Evangelios sinópticos no emplean la palabra, pero sí el proceso de discernir. De hecho, las parábolas suponen un continuo discernimiento: (a) Ser sal o hacerse insípido (Cf. Mt 5, 13), (b) Ojo sano o enfermo (Cf. Mt 6, 22 - 23), (c) Camino espacioso o angosto (Cf. Mt 7, 13 - 14), (d) Edificar sobre la arena o sobre la roca (Cf. Mt 7, 24 - 27), (e) Pescados buenos o malos (Cf. Mt 13, 47 - 50), (f) Invitados de la primera o de la última hora (Cf. Mt 22, 1- 4), (g) Vírgenes sabias o necias (Cf. Mt 25, 1 - 13), (h) Cultivar o desperdiciar talentos (Cf. Mt 25, 14-30), y (i) Reconocer o desconocer al hijo del hombre en sus hermanos desnudos, enfermos o prisioneros (Cf. Mt 25, 31 - 46). Comprender y vivir las parábolas es practicar el discernimiento.

En la tradición de la Iglesia, el tema del discernimiento tiene su fundamento en San Pablo, quien hace de la palabra dokimázein una clave para entender su pensamiento: ¿Cómo reconocer los signos de Dios en una determinada situación y, sobre todo, frente a ciertas opciones? 
* La tríada fe, esperanza y caridad (Cf. 1 Tes 1, 2ss.; 5, 8 - 10; 1 Cor 13, 13; Col 1, 4ss.) constituye la dimensión fundamental en que la existencia cristiana se manifiesta, se realiza y crece en el creyente.

* Por tanto, se presenta la tarea de discernir para percibir continuamente la voluntad de Dios (Cf. Ef 5, 8.10.17).

* Esto se consigue en la medida en que se ha recibido el don del Espíritu (Cf. Rom 8).

* El Espíritu divino entabla un diálogo que invita al individuo a una continua confrontación para dar una respuesta dócil en el contexto de un constante dinamismo de transformación interior y de renovación, para reconocer el sendero que traza Dios y seguirlo.

Así, el discernimiento espiritual ayuda al cristiano para pasar de la edad infantil de la fe a la de la persona madura. ¿Cuáles son los criterios para verificar que una determinada inspiración viene efectivamente de Dios?

1.- Los frutos. El espíritu bueno y el malo se reconocen por sus frutos: "Las obras de la carne son manifiestas: fornicación, impureza, lujuria... Por el contrario, los frutos del Espíritu son: caridad, alegría, paz, longanimidad, benignidad, bondad, fe, mansedumbre, continencia" (Gál 5, 14 - 22. Cf. Ef 5, 8 - 10; Rom 7, 4 - 5.19-20).

2.- La comunión eclesial. Los dones auténticos del Espíritu son los que edifican la Iglesia. Los carismas son dones fecundos para la Iglesia, sobre todo la profecía, la cual es una palabra eficaz que da paz, ánimo y confianza (Cf. 1 Cor 14, 4.12.26).

3.- La fuerza en la debilidad. El Espíritu se manifiesta con signos de poder: milagros, seguridad para proclamar la palabra de Dios y afrontar las persecuciones (Cf. 1 Tes 1, 4 - 5; 2 Cor 12, 12). Son signos que resultan tanto más auténticos cuanto más contrastan con la debilidad del apóstol (Cf. 2 Cor 2, 4; 12, 9).

4.- La inmediatez de Dios. La seguridad de una vocación divina en la docilidad eclesial. Es la experiencia de Pablo comenzada en el camino de Damasco. Por una parte, Dios da la certeza de su vocación (Cf. Rom 1, 1; Gál 1, 15; Flp 3, 12) y, por otra, esa llamada debe ser autentificada por la comunidad eclesial (Cf. Gál 1, 18) y por sus responsables.

5.- La luz y la paz. Los dones del Espíritu no son impulsos ciegos que suscitan dificultades y desorden (Cf. 1 Cor 14, 33). Esto vale no sólo para las manifestaciones extraordinarias, sino también para las mociones interiores: "La tristeza según Dios produce firme arrepentimiento para la salvación; mas la tristeza del mundo produce la muerte" $(2$ Cor 7,10$)$, "porque los bajos instintos tienden a la muerte, el Espíritu tiende a la vida y la paz" (Rom 8, 6. Cf. 14, 17 - 18).

6.- La comunión fraterna. Es el criterio más seguro e importante que revela los signos de la presencia del Espíritu (Cf. 1 Cor 13). La caridad hace también respetar y amar los carismas de los otros (Cf. 1 Cor 12).

A algunos, el Espíritu les concede el carisma del "discernimiento de espíritus" (1 Cor 12, 10), es decir, la capacidad estable y duradera de reconocer si una determinada inspiración viene del Espíritu divino o del espíritu del mal. Mas a todos los creyentes se les da el "don del Espíritu", que se recibe radicalmente con la fe y el bautismo y que "habita en nosotros" (Rom 8, 9) y nos guía, haciéndonos vivir como hijos de Dios (Cf. Rom 8, 14). El Espíritu es, pues, el elemento constitutivo de nuestro ser de cristianos, el principio dinámico y la norma de acción, de los hijos e hijas "en la Iglesia” (1 Cor 12, 13). 
En la Primera Carta de Juan, se advierte a los cristianos para que adopten una actitud crítica frente a "los espíritus": "Queridísimos, no se fíen de todo espíritu, sino examinen los espíritus (dokimázete ta pneumata), a ver si son de Dios" (1 Jn 4, 1). Su evangelio se lee como una lucha entre las tinieblas y la luz (Cf. Jn 1, 5) y llama a Satanás "padre de la mentira" (Jn 8, 44). La carta dice que debemos "distinguir el espíritu de la verdad del espíritu del error" (1 Jn 4, 6).

También, el tema del discernimiento está presente en San Basilio, en San Gregorio de Niza, en los Padres y en las Madres del Desierto, en Diádoco de Fótice, en San Máximo Confesor, en Juan Casiano, en Juan Clímaco, entre otros (Cf. Ruiz Jurado, 2002). La teología tradicional ve, en la oposición de las mociones, la diferencia de origen: las inclinaciones hacia el bien vienen de Dios (la gracia) y las inclinaciones hacia el mal son atribuidas al demonio (concupiscencia, el pecado). Por lo tanto, se presenta el discernimiento como un proceso porque intenta elaborar una criteriología para distinguir las mociones y su proveniencia.

Juan Casiano (siglo V) es el gran maestro espiritual de occidente. En sus "Conferencias" (Collationes), en forma de diálogo, dedica ocho capítulos de la primera conferencia, y toda la segunda, al tema del discernimiento de los espíritus, al que incorpora la idea griega del "nada en demasía", la discreción, la mesura.

Casiano llama a la discreción (diákrisis) "la madre de la mesura” y la opone al "vicio de la desmesura". Es una virtud que inspira y rige todas las demás virtudes, y que debe controlar todas las formas de nuestras acciones: "Ninguna virtud puede mantenerse o perfeccionarse completamente sin la gracia de la discreción. Esta es la madre, la guardiana y la moderadora de todas las virtudes" (Coll 2, 4). La discreción orienta al monje para mantenerlo a igual distancia de los excesos y guiarlo por el camino real, "sin dejarlo que se aparte ni a la derecha en un fervor excesivo sin templanza, ni a la izquierda en la molicie y el relajamiento que llevan a la tibieza espiritual" (Coll 2, 2). Las condiciones esenciales para adquirir la discreción son la humildad y la transparencia de conciencia, que requiere, a la vez, de la humildad (Coll 2, 10).

\section{2.- EL DISCERNIMIENTO IGNACIANO}

Otro gran maestro del discernimiento es Ignacio de Loyola (1491 - 1556). Aunque el término discernimiento no aparece en los escritos ignacianos y tampoco escribe un tratado al respecto, la Autobiografía, los Ejercicios Espirituales y su Diario Espiritual son expresiones de las lecciones que fue aprendiendo en su propia vida y que, posteriormente elaboró, especialmente en sus "Reglas para en alguna manera sentir y conocer las varias mociones que en la ánima se causan, las buenas para recibir y las malas para lanzar” (De Loyola, 1982, n. 313).

Ignacio descubrió, por propia experiencia, que la vida espiritual puede ser ambigua y equivoca. "No fiarse de cualquier espíritu sino de comprobar si los espíritus proceden de Dios" (1 Jn 4, 1. Cf. 1 Tes 5, 19). En su búsqueda por cumplir la voluntad de Dios se encontró con muchos tropiezos, hasta tal punto que, en un momento dado, pensó en el suicidio. En la primera etapa de su conversión, Ignacio se dedica 
a imitar a los santos. En Manresa hace su noviciado, atormentado por distintas mociones. En la visión del Cardoner se le abrieron los ojos del entendimiento y todas las cosas le parecieron nuevas.

Así, el discernimiento ignaciano tiene su fuente en su propia experiencia y así está elaborado en los Ejercicios Espirituales. En su Diario Espiritual se constata el meticuloso cuidado que ponía en expresar lo que 'sentía' y cómo buscaba la palabra precisa que mejor describiera su experiencia. Observaba finamente los efectos que tenían en sí mismo y en sus estados anímicos, los movimientos interiores que sentía.

Los Ejercicios Espirituales, que elaboró y revisó constantemente durante toda su vida, tienen la clara finalidad de "buscar y hallar la voluntad divina" y, para conseguirlo, se precisa remover el desorden afectivo que impide este descubrimiento. En otras palabras, por medio del discernimiento se descubre de dónde vienen las mociones para poder actuar en consecuencia: para 'recibir' unas y 'rechazar' otras. Por ello, parte importante del trabajo de esa discreción de espíritus es reducir esa variedad de vivencias interiores a la diferencia fundamental de su procedencia del buen o del mal espíritu.

En el fondo, los Ejercicios Espirituales son un proceso de liberación, de hacernos y disponible para poder hallar lo que Dios quiere. Por consiguiente, la elección, en los Ejercicios Espirituales, presupone tres actitudes fundamentales: (a) purificación (afectos desordenados), (b) generosidad (magis), y (c) oración (meditaciones y contemplaciones) (De Loyola, 1982, n. 136 - 146).

Ignacio propone tres tiempos de elección, entendiendo la palabra tiempo en el sentido bíblico de kairós (tiempo de gracia):

Primer tiempo: En él, Dios nuestro Señor mueve y atrae la voluntad, de tal manera que, sin duda, el alma devota sigue lo que se le muestra. Así lo hicieron san Pablo y san Mateo, al seguir a Cristo nuestro Señor. Lo que caracteriza este tiempo no es la consolación sin causa, tampoco la consolación en general. Es la certeza y la claridad con que se percibe lo concreto de la elección como voluntad de Dios para uno.

Segundo tiempo: El clásico modo de discernir la voluntad de Dios mediante la dinámica de consolaciones y desolaciones, discernimiento de varios espíritus, llegando a adquirir claridad y conocimiento.

Tercer tiempo: Es la razón iluminada por la fe. No se recurre a una percepción intuitiva (primer tiempo) o a una dialéctica de las inspiraciones (segundo tiempo), sino mediante la depuración de las razones a la luz de la fe. Es fundamental estar tranquilo y en paz.

Confirmación: Puede ser interna (percibir que a Dios le agrada la elección) o externa (confirmación mediante signos históricos de los acontecimientos). (De Loyola, 1982, n. 175 - 176).

En los Ejercicios Espirituales se encuentran algunos requisitos indispensables para entrar en un proceso de discernimiento:

1.- Comunicación con la propia interioridad. Se requiere la capacidad de tomar contacto con el propio mundo interior. Asomarse a esa compleja realidad que tejen nuestras fantasías, nuestras emociones, nuestras voliciones... En el número 313 de los Ejercicios, Ignacio indica la finalidad de las reglas de discernimiento: "para de alguna manera sentir y conocer las varias mociones...la buenas para seguir, 
las malas para lanzar" (n. 313). Solo así se puede llegar a comprenderlas, a aclarar de dónde proceden y a qué conducen.

2.- Reconocer y enfrentar los propios límites. El que discierne necesita conocerse. Si procede a negar tal o cual aspecto de la personalidad, gastará las energías que necesita para el discernimiento en reprimir aspectos que considera indeseables, en negar gustos o repugnancias que son significativos (De Loyola, 1982).

3.- Coraje para hacer el relato de la propia vida. El narrador tiene que situarse más allá del mero suceder y sucederse, a tal punto que pueda darles una configuración a esos acontecimientos. Su elaboración de esas configuraciones, fruto de la operación narrativa, va enseñando a vivir la vida en la búsqueda de una unidad que conjure las dispersiones. Por tanto, hacer el relato de la propia vida es aprender a distinguir los relatos que despiertan esperanza de aquellas que se empantanan en el desencanto y la amargura. $\mathrm{O}$, de otra forma, distinguir los relatos que tienen realismo de aquellos que se alimentan de ilusiones engañosas que terminan luego en decepción. El propio Ignacio confirma la relevancia de esta característica con su Autobiografía. En el segundo ejercicio de la primera semana, sobre el pecado propio, Ignacio pide al ejercitante que haga un relato de su vida de alejamiento de Dios. Pero no para hundirlo en la desesperanza, sino para llenarlo de un profundo agradecimiento por ese amor misericordioso que perdona.

4.- Confianza en la promesa. Esa promesa mira al cumplimiento de los deseos de la profundidad, anhelos hondos del alma, más que a los deseos que responden a necesidades que se agotan en el momento en que son satisfechas. Acoger el llamado al seguimiento implica el anhelo profundo del alma de ser libre, el no tener atadura alguna que responda a mandatos que reemplacen la voz de la promesa con la seguridad. La confianza de que nunca nos faltará la gracia de Dios para llevar a cabo las obras que Él inspira es patente en la vida de Ignacio. En los Ejercicios, lo que Dios quiere es "abrazar en su amor a la ánima devota...disponiéndola por la vía que mejor podrá servirle en adelante".

5.- Generosidad. El contexto del magis. En el mismo texto de los Ejercicios Espirituales se subraya la tónica del magis: "solamente deseando y eligiendo lo que más conduce al fin que somos creados" (De Loyola, 1982, n. 23). Por eso, este primer cuerpo de reglas está hecho para quien camina "en el servicio de Dios de bien en mejor subiendo" (De Loyola, 1982, n. 315). Por ello, el discernimiento también requiere un ámbito de generosidad. Discernir, en estos contextos, significa buscar y encontrar cómo amar más y mejor, y cómo dejarse encontrar por el Señor que viene a mi encuentro.

En el libro de los Ejercicios Espirituales, Ignacio ofrece unas reglas para el discernimiento (De Loyola, 1982, n. 313) en dos etapas: unas corresponden a la primera semana de los ejercicios espirituales, mientras otras para la segunda semana. La diferencia entre las dos series de reglas es que en las correspondientes a la primera semana (etapa de conversión) las tentaciones provenientes del mal espíritu son totalmente abiertas y evidentes, mientras que en las de la segunda semana estas mociones son sutiles (etapa de la invitación al seguimiento radical de la persona de Jesús, el Cristo).

La contribución de Ignacio ha sido la elaboración de un método práctico: individual en los Ejercicios Espirituales y comunitario en las deliberaciones de los primeros padres para fundar la Compañía de Jesús (1539). (Cowan y Futrell, 1982)

La práctica del discernimiento responde a la propia experiencia de Ignacio, es decir, es el fruto de una reflexión sobre su propia experiencia en el proceso de conversión y de crecimiento en la fe. Ignacio reconoce que la dimensión objetiva (la revelación divina plena en Cristo transmitida en la Iglesia) testifica la 
autenticidad de la dimensión subjetiva (el fruto del discernimiento individual). El discernimiento individual es plenamente confirmado solo dentro de la comunidad eclesial. (Cf. Rom 12, 3 - 5).

Las reglas de la primera semana (De Loyola, 1982, n. 313-327) pueden agruparse en torno a cinco temas:

1.- Una descripción del modo de proceder característico del mal y del buen espíritu (N. 314, 315, 327).

2.- Una descripción de los elementos constitutivos de la consolación y de la desolación (N. 316, 317).

3.- Una orientación sobre qué hacer en tiempos de desolación (N. 318, 319, 320, 324, 325, 326).

4.- Una explicación sobre las causas de la desolación (N. 322).

5.- Una orientación sobre qué hacer en tiempos de consolación. (N. 323, 324).

La mayoría de las reglas para la primera semana están relacionadas con aconsejar sobre cómo enfrentar la desolación, dado que, durante este tiempo, el tema clave es la conversión, pasando por una reflexión sobre el propio pecado y los afectos desordenados.

Ignacio distingue el modo de proceder característico del buen y del mal espíritu según la orientación básica de la persona. Si una persona se encuentra lejos de Dios, la fuerza del mal ataca mediante unos deseos que se dirigen hacia acciones contrarias al amor de Dios y del prójimo, como resultado del autocentrarse y del auto-amor. El mal espíritu ataca donde la persona se encuentra más vulnerable. Por ello, es importante realizar diariamente el examen particular. Por el contrario, si una persona se esfuerza para acercarse a Dios, la fuerza del mal ataca mediante la ausencia de paz. (De Loyola, 1982).

El discernimiento espiritual examina los movimientos internos. Las acciones externas son el fruto de las mociones internas y, justamente, "por sus frutos lo reconocerán" (Mt 7, 16. Cf. Gál 5, 16 - 25). Por consiguiente, el proceso de discernimiento tiene la finalidad de descubrir el origen de las acciones y para ello es preciso detectar su orientación básica: si aleja o si acerca a Dios y a los demás.

El proceso de discernimiento requiere la capacidad de reconocer los propios sentimientos, lo cual no es nada fácil ya que, algunas veces, se ha educado más bien en su represión.

* La consolación significa la paz interior, el gozo espiritual, la esperanza, la fe, la caridad, las lágrimas, el elevar la mente. Estos son frutos del Espíritu. ${ }^{2} \mathrm{~A}$ la vez, es preciso saber distinguir los distintos niveles de los sentimientos para diferenciar lo más superficial y efímero de la intuición y el gozo profundos. (De Loyola, 1982, n. 316).

* La desolación implica lo contrario: guerra contra paz, tristeza contra gozo, esperanza en cosas terrenales contra aquellas celestiales, amor bajo contra amor sublime, sequedad contra lágrimas, distracción contra elevación. Así también, los pensamientos que brotan de la consolación son opuestos a aquellos que surgen de la desolación. (De Loyola, 1982, n. 314-317).

2 Cf. Directoria Exercitiorum Spiritualium, 1540 - 1599 de Polanco (secretario de Ignacio). 
Las reglas tienen una finalidad pedagógica para aprender de la propia experiencia y prepararse para la elección. La primera regla es la de no tomar ninguna decisión en tiempos de desolación. Uno encuentra a Dios en la paz. Por ello, en momentos de tempestad es preciso quedarse con las decisiones asumidas durante la consolación.

También, se requiere luchar contra la desolación mediante la oración y el ayuno. Dios permite la desolación para el crecimiento del individuo. En este tiempo se sugiere recordar la consolación y la ayuda incesante de Dios. Es el agere contra. En este tiempo se hace necesaria la presencia del acompañante espiritual: confiar en él y dejarse guiar por él.

Ignacio señala tres causas de la desolación: (a) la propia responsabilidad, (b) una prueba de Dios ${ }^{3}$, y (c) la purificación pasiva obrada por Dios. Mediante el examen de conciencia se descubre si uno se está resistiendo a la gracia. En caso contrario, puede ser una pedagogía divina (b) para buscar a Dios en sí mismo y no a uno mismo; en este caso, hay que perseverar. En el tercer caso (c), hay que abandonarse a las manos de Dios, reconociendo la propia pobreza (la experiencia de San Juan de la Cruz).

En la consolación hay que prepararse para la desolación, reconociendo que la consolación es un don de Dios.

En las reglas correspondientes a la segunda semana de los ejercicios espirituales se destaca, básicamente, el peligro del sub angelis lucis, es decir, ser tentado por lo aparentemente bueno. En esta semana hay tres temas principales:

1.- Una descripción del modo de proceder característico del buen y del mal espíritu.

2.- Una explicación del discernimiento sobre el origen de una consolación causada, en cuanto surge del buen o del mal espíritu mediante el descubrimiento de su orientación

3.- Una explicación sobre el reconocimiento de una consolación proveniente de Dios.

La auténtica consolación aleja la tristeza y la angustia. El mal espíritu acude a malas razones para entristecer la consolación. Cuando la persona está orientada hacia Dios, el mal espíritu aparece como un ángel de la luz regalando una falsa consolación para alejar a la persona de Dios. Así, sentirse llamado a vivir en mayor pobreza y terminar amargado; ser más profético y acabar siendo fariseo; optar por una vida de oración más intensa y caer en el orgullo. Lo que comienza bien, termina mal. Por ello, resulta clave discernir el origen (desde dónde) de la consolación para detectar su orientación (hacia dónde), es decir, si acerca o aleja de Dios. (De Loyola, 1982).

Hay que reflexionar cuidadosamente sobre la evolución del propio pensamiento: cómo comienza, cómo progresa y cómo termina. Si eventualmente aleja de Dios, es del mal espíritu. La tranquilidad inicial

3 "Ninguno cuando sea probado, diga: Es Dios quien me prueba; porque Dios ni es probado por el mal ni prueba a nadie. Sino que cada uno es probado por su propia concupiscencia que le arrastra y le seduce. Después la concupiscencia, cuando ha concebido, da a luz el pecado; y el pecado, una vez consumado, engendra la muerte" (Sant 1, 13 - 15). 
cede a la inquietud en el corazón. Por ello, hay que considerar el final o el resultado y retroceder hacia atrás para averiguar si algo que comenzó como bueno terminó mal. (De Loyola, 1982).

Si una persona se encuentra orientada hacia Dios, la acción del Espíritu se percibe como una gota que penetra una esponja, mientras el mal espíritu irrumpe violentamente, y con ruido, como una gota que cae sobre una piedra.

Una consolación sin causa proviene de Dios, es decir, cuando no hay una causa proporcional en la percepción y el conocimiento. Es una experiencia en el contexto de la gratuidad y la pasividad. Hay dos características al respecto: (a) se sabe por experiencia que no es posible conseguir esta consolación mediante ninguna técnica o actividad intencionada, aunque uno puede prepararse y esperar, pero no es posible causarla porque se experimenta como gratuita; (b) es la experiencia de una presencia misteriosa, pero real, inmanente y trascendente porque es la experiencia de llegar a casa.

Ignacio advierte contra su prolongación en el tiempo para distinguirla de la actual consolación, ya que, en el tiempo, puede confundir la propia voluntad con la de Dios. Por ello, insiste en la confirmación en el tiempo.

Por consiguiente, los ejes del discernimiento ignaciano son:

* El objeto inmediato del discernimiento: las mociones internas para motivar la acción: pasiones, pensamientos, sentimientos.

* La finalidad del discernimiento: detectar el origen de las mociones: cuáles provienen del Espíritu y cuáles no para seguir aquellas del Espíritu.

* Los medios para alcanzar esta finalidad: descubrir la orientación de una moción hacia la acción: ‘aleja o acerca a Dios?

* El descubrimiento de esta orientación: la reflexión sobre (a) la auténtica interpretación de la propia experiencia del pasado; (b) los datos de la experiencia presente, y (c) el ya discernido futuro que consiste en la propia vocación.

Por ello, el discernimiento es básicamente una más auténtica vivencia de la propia vocación. Es el resultado de una liberación interior que conduce a un encuentro con Dios, mediante una elección personal, como respuesta a la llamada de Dios. Discernir es encontrar a Dios en todas las cosas: esta es la finalidad de la dinámica de los Ejercicios Espirituales de Ignacio de Loyola.

Desde una perspectiva ética, vale la pena subrayar cómo Ignacio, en los Ejercicios Espirituales, pone en práctica la primacía de la conciencia. Él acompaña al ejercitante en el camino y enseña el modo de no equivocarse siguiendo la conciencia. Es decir, coloca a la luz del discernimiento para que el ejercitante pueda acertar en este difícil itinerario y encontrar el paso justo.

Respetuoso en grado sumo con la conciencia, no impone su modo de pensar, ni siquiera exhorta. Su táctica es poner a Dios con el ejercitante. Dios mismo se manifestará, se dejará sentir. No es un paternalista que mantiene las riendas para dominar la situación. Señala la dirección. Como un guía, da las advertencias convenientes y luego deja al sujeto con Dios. 
Son interesantes a este propósito las adiciones a los Ejercicios Espirituales, donde explica, en detalle, lo que hay que hacer antes de la oración: la postura que hay que adoptar, los pensamientos más convenientes para prepararse adecuadamente, etc. Pero, después, se retira en el momento en que se inicia el contacto con Dios en la oración. Ignacio deja al ejercitante con Dios. Sería entrometerse en el sagrado recinto de la conciencia de otro, imponerse en ese momento sagrado. Solo antes puede realizarlo pues estima tanto la conciencia que desea educarla, prepararla.

\section{3.- EL DISCERNIMIENTO EN EL PENSAMIENTO DEL PAPA FRANCISCO}

La mirada pastoral que predomina en el papa Francisco, una perspectiva de cercanía a las personas concretas, conduce a la recuperación del papel de la conciencia; por ende, la importancia decisiva del discernimiento en sus escritos.

La comprensión del ethos cristiano como fruto y expresión de la espiritualidad, es decir, coherencia y consecuencia con la fe vivida y proclamada, hace que en el magisterio del papa Francisco se subraye la importancia decisiva de la formación y el recurso a la conciencia, para poder ejercer de manera responsable la libertad humana.

"El avance moral", escribe Julio Luis Martínez s.j., "no se logra con recetarios de normas o principios generales que el Magisterio confecciona diligentemente, sino acogiendo, acompańando, discerniendo e integrando, en un humus impregnado de misericordia tanto en las relaciones como en las enseńanzas" (2017, pp. 377-78). Es que, como escribe Santo Tomás de Aquino (1994), "en las cosas prácticas se encuentra mucha incertidumbre, por el actuar sobre situaciones singulares y contingentes que por su variabilidad resultan inciertas" (I-II, q. 14, a. 1).

Por ello, el Papa Francisco estima que:

La conciencia de las personas debe ser mejor incorporada en la praxis de la Iglesia", especialmente en aquellas situaciones complejas cuando una persona "puede reconocer con sinceridad y honestidad aquello que, por ahora, es la respuesta generosa que se puede ofrecer a Dios, y descubrir con cierta seguridad moral que esa es la entrega que Dios mismo está reclamando en medio de la complejidad concreta de los límites, aunque todavía no sea plenamente el ideal objetivo. (Francisco, 2016, no. 303).

Obviamente, se trata de una conciencia que se abre a un discernimiento dinámico, permaneciendo abierta a nuevas etapas de crecimiento y a nuevas decisiones que permitan realizar el ideal de manera más plena.

El problema, señala el Pontífice, es que:

Nos cuesta dejar espacio a la conciencia de los fieles, que muchas veces responden lo mejor posible al Evangelio en medio de sus límites y pueden desarrollar su propio discernimiento ante situaciones donde se rompen todos los esquemas. Estamos llamados a formar las conciencias, pero no a pretender sustituirlas. (Francisco, 2016, no. 37). 
La vida de fe del cristiano implica una búsqueda de la voluntad divina en la historia humana. ¿Qué es lo que Dios quiere? ¿Qué es lo que Dios está diciendo en una situación concreta? Por tanto, la conciencia del cristiano tiene la voluntad de Dios como principal referente.

Esto es el discernimiento: "la mirada del discípulo misionero, que se alimenta a la luz y con la fuerza del Espíritu Santo" (Francisco, 2013, no. 50); el discernimiento orienta "a la toma de conciencia de su situación ante Dios" (Francisco, 2016, no. 300). Por tanto, "este discernimiento no podrá jamás prescindir de las exigencias de verdad y de caridad del Evangelio propuesto por la Iglesia” (Francisco, 2016, no. 300).

El discernimiento no es tanto un acto puntual cuanto un proceso constante porque el cristiano: "sabe que él mismo tiene que crecer en la comprensión del Evangelio y en el discernimiento de los senderos del Espíritu, y entonces no renuncia al bien posible, aunque corra el riesgo de mancharse con el barro del camino" (Francisco, 2013, no. 45).

En medio de las situaciones concretas, "el discernimiento debe ayudar a encontrar los posibles caminos de respuesta a Dios y de crecimiento en medio de los límites", de lo contrario, "por creer que todo es blanco o negro a veces cerramos el camino de la gracia y del crecimiento, y desalentamos caminos de santificación que dan gloria a Dios" (Francisco, 2016, no. 305). Por consiguiente, se propone:

Un responsable discernimiento personal y pastoral de los casos particulares, que debería reconocer que, puesto que el grado de responsabilidad no es igual en todos los casos, las consecuencias o efectos de una norma no necesariamente deben ser siempre las mismas. (Francisco, 2016, no. 300)

El recurso al discernimiento no es sólo personal sino también comunitario:

En su constante discernimiento, la Iglesia también puede llegar a reconocer costumbres propias no directamente ligadas al núcleo del Evangelio, algunas muy arraigadas a lo largo de la historia, que hoy ya no son interpretadas de la misma manera y cuyo mensaje no suele ser percibido adecuadamente. Pueden ser bellas, pero ahora no prestan el mismo servicio en orden a la transmisión del Evangelio. No tengamos miedo de revisarlas. Del mismo modo, hay normas o preceptos eclesiales que pueden haber sido muy eficaces en otras épocas pero que ya no tienen la misma fuerza educativa como cauces de vida. Santo Tomás de Aquino destacaba que los preceptos dados por Cristo y los Apóstoles al Pueblo de Dios 'son poquísimos' (cf. Suma Teológica, 1994, I-II, q. 107, art. 4). (Francisco, 2013, no. 43)

Por ello, el Pontífice recomienda:

A partir del reconocimiento del peso de los condicionamientos concretos, podemos agregar que la conciencia de las personas debe ser mejor incorporada en la praxis de la Iglesia en algunas situaciones que no realizan objetivamente [lo ideal] ... Ciertamente, que hay que alentar la maduración de una conciencia iluminada, formada y acompañada por el discernimiento responsable y serio del pastor, y proponer una confianza cada vez mayor en la gracia. (Francisco, 2016, no. 303)

Por ello, resulta indispensable la formación de la conciencia. "La conciencia es camino de toda una vida, en el que se aprende a nutrir los sentimientos propios de Jesucristo, asumiendo los criterios de sus decisiones y las intenciones de su manera de obrar (cf. Flp 2, 5)" (Francisco, 2019, no. 281). 


\section{4.- EL DISCERNIMIENTO ÉTICO}

Si el discernimiento es la búsqueda de la voluntad de Dios en lo concreto de una situación determinada, entonces el discernimiento es el puente entre la ética y la espiritualidad. En otras palabras, el ethos cristiano pertenece al ámbito conciliar de los signos de los tiempos (esta historia es una de salvación y los momentos de kairós iluminan la lectura ética de la realidad).

El cristiano es capaz de discernir en la medida en que "se deja transformar por la nueva mentalidad" (Rom 12,2.). El objeto del discernimiento no es la ley ni un conjunto de principios, porque su cometido es la búsqueda de la voluntad de Dios (Cf. Rom 12, 2). Esta búsqueda demuestra su autenticidad en la transformación efectiva del sujeto (Cf. Rom 12, 2: no se amolden; Fil 1, 10 - 11: sinceridad).

"Si por la ley se obtuviera la justificación, entonces hubiese muerto Cristo en vano" (Gál 2, 21), escribe san Pablo, y, por ello, insiste que la ley es nuestra pedagoga hasta llegar a Cristo, pero una vez llegada la fe, ya no se está bajo la pedagoga (Cf. Gál 3, 24 - 25). En otras palabras, la ética cristiana se distingue por, en palabras de Juan Pablo II (1993): "el nexo intrínseco e indivisible entre fe y moral" (no. 4). Es decir, la espiritualidad se hace ética y la ética se fundamenta en la espiritualidad.

Juan Crisóstomo (347 - 407), en el preámbulo a su comentario al Evangelio de San Mateo, explica:

Nuestra vida debería ser tan pura que no tuviera necesidad de ningún escrito; la gracia del Espíritu Santo debería sustituir a los libros, y así como éstos están escritos con tinta, así también nuestros corazones deberían estar escritos con el Espíritu Santo. Sólo por haber perdido esta gracia tenemos que servirnos de los escritos; pero Dios mismo nos ha mostrado claramente cuánto mejor sería el primer modo (...). A sus discípulos, en efecto, Dios no les dejó nada por escrito, sino que les prometió la gracia del Espíritu Santo: 'El - les dijo - os lo sugerirá todo'... Pues es el Espíritu Santo el que bajó del cielo cuando fue promulgada la nueva ley, y las tablas que él grabó en esta ocasión son muy superiores a las primeras; los apóstoles no bajaron del monte llevando, como Moisés, tablas de piedra en sus manos, sino que lo que llevaban era el Espíritu Santo en sus corazones, convertidos mediante su gracia en ley y libro vivientes (Crisóstomo, . 1, n. 1 , PG 57, $13-15)$.

Posteriormente, Tomás de Aquino (1225 - 1274) insiste en la misma perspectiva del ethos cristiano.

Dice el Filósofo que 'cada cosa se denomina por aquello que en ella es principal'. Ahora bien, lo principal en la ley del Nuevo Testamento y en lo que está toda su virtud es la gracia del Espíritu Santo, que se da por la fe en Cristo. Por consiguiente, la ley nueva principalmente es la misma gracia del Espíritu Santo, que se da a los fieles de Cristo... Tiene, sin embargo, la ley nueva ciertos preceptos como dispositivos para recibir la gracia del Espíritu Santo y ordenados al uso de la misma gracia, que son como secundarios en la ley nueva, de los cuales ha sido necesario que fueran instruidos los fieles de Cristo, tanto de palabra como por escrito, ya sobre lo que se ha de creer como sobre lo que se ha de obrar. Y así conviene decir que la ley nueva es principalmente ley infusa; secundariamente es ley escrita (De Aquino, I-II, q. 106, art. 1).

La experiencia religiosa se traduce en un estilo de vida: de la fe a la moral, una coherencia y una consecuencia entre lo que se profesa y lo que se hace. El encuentro se hace acción. El cristianismo no es primariamente una moral sino fundamentalmente un ámbito de sentido trascendente (la fe) y de celebración 
(la esperanza), que conducen a un determinado estilo de vida (la caridad). La fe actúa por la caridad (Cf. Gál 5, 6), la fe se hace caridad.

La ética cristiana es una llamada de coherencia entre la fe que se profesa y el estilo de vida que se asume. "Aunque repartiera todos mis bienes y entregara mi cuerpo a las llamas, si no tengo caridad, nada me aprovecha" (1 Cor 13, 3). En palabras de Benedicto XVI (2005): "No se comienza a ser cristiano por una decisión ética o una gran idea, sino por el encuentro con un acontecimiento, con una Persona, que da un nuevo horizonte a la vida y, con ello, una orientación decisiva” (No. 1). La autenticidad del encuentro se verifica (se hace verdad) en el comportamiento (la ética). La coherencia entre el ser cristiano (identidad) y el actuar como cristiano (misión).

Una manera de comprender la ética cristiana es recurriendo a uno de los significados griegos de la palabra ethos, que es morada u hogar. La ética pretende que el sujeto sea un hogar para sí mismo y, por ende, podrá ser un hogar para otro y colaborar a que el mundo sea un hogar para todos. Así, la ética pretende construir un discurso - mediante la propuesta del universo de sentidos, de ideales y de valores - que haga posible y viable (habitable) la condición humana en la sociedad. El desafío de la ética es el hacerse cargo de la realidad para que sea un hogar de todos y cada uno; a su vez, también para que cada uno sea un hogar en sí mismo y para otros.

En la perspectiva cristiana, este concepto de hogar se define según los criterios del Evangelio, tal como fue transmitido desde las primeras comunidades cristianas y ratificado por el Magisterio de la Iglesia.

\section{5.- EL DISCERNIMIENTO COMO MÉTODO ÉTICO}

Etimológicamente, método deriva de las palabras metá (hacia) y odós (camino). Por consiguiente, el término podría traducirse como el camino a recorrer para conseguir un resultado determinado. En el ámbito del discernimiento ético, la pregunta es cómo formar un juicio ético sobre el comportamiento humano. En palabras de Tomás de Aquino: "En las cosas prácticas se encuentra mucha incertidumbre, porque el actuar sobre situaciones singulares y contingentes, por su misma variabilidad, resultan inciertas" (1994, I-II, q. 14, art. 1).

Es preciso distinguir entre la universalidad de los principios (dice relación a la persona humana) y la contextualización de la ley (dice relación a la persona en una situación concreta), porque la condición humana es inmutable, pero tiene una expresión cambiante en la historia. La presencia de la norma responde a la sociabilidad del ser humano y, además, tiene una función pedagógica, pero no debería convertirse en un absoluto en sí misma. En palabras de Jesús el Cristo: "La ley está para el hombre y no el hombre para la ley" (Mc 2, 27).

Karl Rahner s.j. distingue entre principios e imperativos No todo principio es ya, por ello mismo, un imperativo, porque un principio se sitúa en el nivel de lo universal, pero una norma obliga al individuo... En otras palabras, es posible que se exija de una persona particular (el singular) algo que no se pueda exigir de todas las personas humanas (el universal) que se encuentran en situaciones similares, algo que no se 
puede exigir de la persona por ser persona humana (ética universal), o por hacer parte de una comunidad particular (costumbres y normas éticas de una comunidad) sino sencillamente por ser aquella persona única e irrepetible en todo el universo y en toda la historia. (1963, p.14-45).

Rahner pone luego un ejemplo de alguien (un singular humano) que tiene que elegir entre ser médico o ser sacerdote. Si esta persona fuera simplemente un caso particular de la esencia 'Homo sapiens', estas dos opciones serían igualmente lícitas para él, moralmente. Pero, dado que una persona es más que una copia de un universal, una elección de este tipo no es existencial y éticamente irrelevante: esta elección determina el ser de este individuo y es necesaria, aquí, una autentica toma de decisión.

Así, Rahner establece una diferencia entre principios e imperativos: los imperativos tocan a lo individual humano y no solo al universal (como los principios), y por eso se conocen, no solo por deducción desde proposiciones que describen las esencias (el conjunto del género humano, la naturaleza...), sino también desde las experiencias existenciales de los individuos, a través de un trabajo de discernimiento. Por tanto, el discernimiento es, en la vocación cristiana, al mismo tiempo, ético y espiritual.

Ahora bien, la mayoría de las decisiones éticas en la vida cotidiana no consisten tanto en optar entre un mal y un bien, sino en la implementación de un bien o el rechazo de un mal en una situación concreta y compleja. Además, en el contexto de las sociedades abiertas y plurales, el discernimiento resulta clave porque se vive cada vez, con más fuerza, lo incierto.

Siguen siendo muy válidas y relevantes las palabras paulinas: "No se acomoden al mundo presente, antes bien transfórmense mediante la renovación de su mente, de forma que puedan discernir cuál es la voluntad de Dios: lo bueno, lo agradable, lo perfecto" (Rom 12, 2).

Tradicionalmente, en la reflexión de la ética cristiana se encuentran dos posturas metodológicas para llegar a un juicio ético en una situación concreta: (a) la deontología (la aplicación de una norma independiente de la situación concreta), y (b) la teleología (la consideración de las consecuencias de un acto).

De alguna manera, ambas posturas se necesitan mutuamente porque la norma no puede descartar totalmente la situación concreta, ya que esta define el contenido y el significado del acto. Así, el beso es un signo de amistad, pero el beso de Judas fue uno de traición porque es el contexto concreto que da el significado al acto. Por otra parte, la teleología necesita un parámetro axiológico normativo para poder evaluar y definir las consecuencias de un acto.

Aún más, ambas posturas centran su reflexión principalmente en la acción moral (deontología) o en sus consecuencias (teleología), más que en el sujeto moral. Al fijarse unilateralmente en la acción, se corre el peligro de subrayar excesivamente la norma que, justamente, tipifica la acción, corriendo el peligro de no dejar en claro la función pedagógica necesaria, pero jamás salvífica. Por el contrario, el discernimiento centra la reflexión moral en el sujeto, rescatando, a la vez, la función pedagógica de la ley, sin reemplazar la centralidad de la conciencia.

No se puede negar el peligro del autoengaño de un subjetivismo que hace coincidir la voluntad de Dios con la propia, buscando en el fondo - y quizás inconscientemente - la satisfacción de los propios intereses. 
Es decir, confundir el discernimiento con la conveniencia. Pero tampoco se puede olvidar el otro peligro opuesto, igual de nefasto, del legalismo, que consiste en el cumplimiento escrupuloso de la ley, la propia seguridad y la auto-justificación frente a la salvación gratuita. ${ }^{4}$ Por ello, resulta clave y esencial comprender a fondo el significado del término discernimiento.

El objeto y el objetivo del discernimiento ético cristiano es la voluntad de Dios, mediante la búsqueda de lo bueno, lo agradable y lo perfecto, para realizar siempre lo mejor. La finalidad de la ley es pedagógica en cuanto ayuda al discernimiento, pero en ningún momento puede sustituirlo ya que, en este caso, no sería una decisión libre ni responsable. A su vez, el discernimiento forma parte de la estructura ética del sujeto porque, en relación con su responsabilidad, se sitúa en el ámbito de la opción fundamental y constituye el ejercicio de la conciencia. La decisión ética es fruto del proceso del discernimiento porque busca aclarar la procedencia de las mociones que se presentan al sujeto o, en otras palabras, aclara el dilema que complica la decisión.

Por consiguiente, se pueden ofrecer algunos criterios como requisitos para un discernimiento ético cristiano:

* Estar en proceso de conversión: el "transformarse" para "distinguir cuál es la voluntad de Dios" (Rom 12, 2. Cf. Ef 5, 17) implica una renovación que afecta a la totalidad de la persona, e incluye una nueva manera de amar, de entender y de enjuiciar; sin conversión no es posible un discernimiento ético cristiano adecuado y consecuente porque solo en el proceso de la conversión se adquiere una nueva mentalidad.

* Tener una recta intención: en todo momento tener la suficiente distancia frente a los propios intereses y los deseos, evitando el autoengaño, mediante una clara opción por la voluntad de Dios, sea esta cual sea (la indiferencia ignaciana).

* Estar atento a los frutos del Espíritu: "El fruto del Espíritu es amor, alegría, paz, paciencia, afabilidad, bondad, fidelidad, mansedumbre, templanza; contra tales cosas no hay ley" (Gál 5, 19-23. Cf. Ef 5, 9; Sant 3, 17).

* Desde una actitud solidaria: como miembro de una sociedad, de un grupo humano. La parábola del juicio final. "Les aseguro que todo lo que le hicieron a uno de estos hermanos míos más pequeños me lo hicieron a Mî" (Mt 25, 40).

Por tanto, el discernimiento constituye un proceso, más que un momento puntual, avalado por un estilo de vida cimentado en una profesión viva de fe en la persona de Jesús, como el Cristo. El discernimiento presupone la espiritualidad y el fundamento de la ética cristiana es la espiritualidad (el encuentro se torna compromiso). A su vez, el discernimiento ético versa sobre los medios que conducen al fin. No se discierne el fin (el horizonte de los valores) sino que se pregunta sobre los medios que conducen al fin (la realización histórica del valor) en una situación concreta y determinada. En otras palabras, el discernimiento ético en relación con el fin situado, la realización del fin en un contexto histórico.

4 Ver la parábola del fariseo y el publicano en Lc 18, 9 - 14. 
También, la lectura ética presupone una comprensión antropológica, tomando en cuenta los tres referentes del ser humano: (a) un yo, en constante relación con los otros (b) dentro de un contexto social (c). En términos teológicos, estos tres referentes se tornan criterios para una lectura ética de la realidad: (a) la condición de hijos (la dignidad de toda y cada persona humana); (b) la actitud de hermandad hacia el otro (el respeto por los derechos humanos y la obligación de los deberes humanos); y (c) la responsabilidad social frente a las relaciones humanas estructuradas y el medio ambiente (el compromiso con la justicia). Asimismo, la opción por los marginados o por los vulnerables constituye la verificación práctica de las tres categorías y la solidaridad, como estilo de vida, es la consecuencia, porque solo desde la inclusión se puede hablar de la totalidad.

Este marco axiológico ilumina el contenido del método. Inspirándose en la espiritualidad ignaciana (experiencia - reflexión - acción) y la teoría de Lonergan (2006) sobre el método en teología, se pueden señalar cuatro pasos o etapas en la formación de un juicio ético: (a) el hecho, (b) su comprensión, (c) los valores implicados, y (d) la acción correspondiente. En otras palabras, (a) la aclaración del hecho/situación puntual; (b) su máxima comprensión en su contexto más amplio; (c) la reflexión sobre los valores implicados; y (d) el procedimiento a una decisión concreta que mejor realiza el valor en la situación concreta.

\begin{tabular}{|c|}
\hline EL HECHO \\
\hline $\begin{array}{l}\Rightarrow \text { ¿Cuál es el hecho? } \\
\Rightarrow \text { ¿Cuál es la pregunta ética del hecho? } \\
\Rightarrow \text { Delimitar la temática } \\
\Rightarrow \text { Objetivar la experiencia (personal y colectiva) } \\
\Rightarrow \text { Objetivar los sentimientos (personales y colectivos) }\end{array}$ \\
\hline LA COMPRENSIÓN DEL HECHO \\
\hline $\begin{array}{l}\Rightarrow \text { Buscar el significado de los datos para formular el hecho en un todo coherente } \\
\Rightarrow \text { Aproximación interdisciplinaria para (a) mayor comprensión del hecho (el significado de los datos); (b) sus } \\
\text { implicaciones; y (c) sus consecuencias } \\
\Rightarrow \text { Considerar el hecho desde el punto de vista de todos los actores sociales involucrados. } \\
\Rightarrow \text { Reconocer el mundo de los sentimientos involucrados, sea personales sea colectivos } \\
\Rightarrow \text { Objetivar el imaginario colectivo y contrastarlo con la realidad del hecho } \\
\Rightarrow \text { Objetivar las influencias significativas del contexto personal y social }\end{array}$ \\
\hline LOS VALORES INVOLUCRADOS (el juicio ético) \\
\hline $\begin{array}{l}\Rightarrow \text { ¿Qué es lo correcto? No se trata de lo conveniente ni de la dictadura estadística, sino del juicio ético } \\
\Rightarrow \text { ¿Cuál es la voluntad divina? El discernimiento ético cristiano } \\
\Rightarrow \text { ¿Qué se ha reflexionado al respecto? (reseña histórica de pensamiento ético) } \\
\Rightarrow \text { ¿Qué se reflexiona hoy? (reseña de posturas éticas actuales) } \\
\Rightarrow \text { Saber seleccionar (relevancia), contextualizar (comprensión) y distinguir (distintos horizontes pueden ser } \\
\quad \text { complementarios, evolutivos o excluyentes) } \\
\Rightarrow \text { ¿Qué dice la Sagrada Escritura y la Tradición? ¿Qué ha sido ratificado por el Magisterio? } \\
\Rightarrow \text { Jerarquización de valores (se discierne porque hay conflicto de valores) }\end{array}$ \\
\hline
\end{tabular}

5 Cf. John Rawls, $A$ Theory of Justice, (1971): Cualquier miembro de la sociedad hubiera escogido aquella sociedad, aún si la persona no supiera que posición ocuparía en la sociedad, incluyendo la menos aventajada. 


\section{LA DECISIÓN (acción ética)}

$\Rightarrow$ Asumir una opción ética

$\Rightarrow$ Traducción práctica de opciones vitales

$\Rightarrow$ Tensión entre lo viable real y lo profético ideal (lo ideal que estimula lo real sin pedir lo imposible: la ley de la gradualidad y de la prudencia)

$\Rightarrow$ Prioridad axiológica (debido al conflicto de valores)

$\Rightarrow$ Comunicación de propuesta cristiana compartiendo significado cognitivo (conocerlo) y efectivo (practicarlo)

$\Rightarrow$ Comunicación como alternativa cristiana que busca la acción transformadora

Por último, la viabilidad de este método presupone algunas condiciones previas:

\section{1.- Deseo de auto trascenderse para buscar:}

(a) objetivamente (lo que haría cualquier otro en el mismo lugar);

(b) evangélicamente (desde el horizonte de conversión, cuando el Evangelio llega a ser criterio de decisiones éticas);

(c) la acción transformadora.

\section{2.- Psicológicamente:}

(a) conocimiento evaluativo (capacidad racional, reflexiva, analítica y crítica);

(b) libertad (reconociendo limitaciones para poder actuar con mayor libertad dentro de los límites);

(c) empatía (preocupación por los otros y adhesión afectiva a decisiones).

\section{3.- Éticamente:}

(a) desde la fe a la moral (expresión de experiencia);

(b) primacía de una conciencia formada (recta, veraz, cierta) (dimensión subjetiva);

(c) iluminada por la mediación pedagógica de la ley (dimensión comunitaria).

\section{6.- EL PROCESO ÉTICO COMO CRECIMIENTO EN LA FE}

En Amoris laetitia, el papa Francisco recuerda que la misión de la Iglesia no consiste en condenar, sino en difundir la misericordia a todas aquellas personas que la piden con corazón sincero. "Nadie puede ser condenado para siempre, porque esa no es la lógica del Evangelio" (Francisco, 2016, no. 297). Por tanto, "hay que evitar los juicios que no toman en cuenta la complejidad de las diversas situaciones, y hay que estar atentos al modo en que las personas viven y sufren a causa de su condición" (Francisco, 2016, no. 296). Es un pensamiento eclesiológico que asume la lógica evangélica de la integración a la comunidad.

Por ello, el papa Francisco entiende por ley de gradualidad más bien una ley de crecimiento.

Sin disminuir el valor del ideal evangélico, hay que acompañar con misericordia y paciencia las etapas posibles de crecimiento de las personas que se van construyendo día a día... Un pequeño paso, en medio 
de grandes límites humanos, puede ser más agradable a Dios que la vida exteriormente correcta de quien transcurre sus días sin enfrentar importantes dificultades. (Francisco, 2013, no. 44)

En otras palabras, el punto de referencia no es la ley sino el ideal evangélico. La gradualidad supone la coincidencia con la ley. La referencia al ideal evangélico hace referencia a la idea de crecimiento. Es decir, la ley no es ya el único parámetro para valorar el progreso de la persona en el camino del bien. En este sentido, sería más adecuado hablar de ley del crecimiento que de ley de la gradualidad.

El papa Francisco está muy consciente de que algunas personas prefieren normas más claras y precisas: "Comprendo a quienes prefieren una pastoral más rígida que no dé lugar a confusión alguna" (Francisco, 2016). Sin embargo, confiesa que cree:

Sinceramente que Jesucristo quiere una Iglesia atenta al bien que el Espíritu derrama en medio de la fragilidad: una Madre que, al mismo tiempo que expresa claramente su enseñanza objetiva, no renuncia al bien posible, aunque corra el riesgo de mancharse con el barro del camino. (2016).

Es preciso "asumir la lógica de la compasión con los frágiles y a evitar persecuciones o juicios demasiado duros o impacientes. El mismo Evangelio nos reclama que no juzguemos ni condenemos (cf. Mt 7, 1; Lc 6, 37)" (Francisco, 2016, no. 308). Es que "ponemos tantas condiciones a la misericordia que la vaciamos de sentido concreto y de significación real, y esa es la peor manera de licuar el Evangelio" (Francisco, 2016, no. 311).

La Iglesia, recuerda el Pontífice, "no es una aduana, es la casa paterna donde hay lugar para cada uno con su vida a cuestas" (Francisco, 2016, no. 310). Esto significa que es preciso superar "una fría moral de escritorio al hablar sobre los temas más delicados, y nos sitúa más bien en el contexto de un discernimiento pastoral cargado de amor misericordioso, que siempre se inclina a comprender, a perdonar, a acompañar, a esperar, y sobre todo a integrar" (Francisco, 2016, no. 312).

El tema del discernimiento es el puente entre la espiritualidad y la ética porque traduce la experiencia de la fe en un estilo de vida cuando el encuentro se hace compromiso, el sentido se hace acción y la palabra se hace vida.

$6 \mathrm{Al}$ respecto, los obispos japoneses en su declaración Mirada de Dios sobre la vida (2017), escriben: "Nosotros tenemos que reconocer, arrepintiéndonos, que la iglesia se ha venido comportando hasta hace poco más bien como juez que como madre, por lo que se refiere a las personas que no han podido salvar su matrimonio. Pero hoy pensamos que se debe acoger y abrazar cálidamente, como hizo Jesucristo, el sufrimiento de las personas, y que debemos apoyarlas y animarlas, acompañándolas en el camino para rehacer de nuevo su vida” (Masiá, 2017). 


\section{Referencias}

Aquino, T. (1994). Suma de Teología. Madrid: Biblioteca de Autores Cristianos.

Benedicto XVI. (2005). Deus caritas est,.

Cowan, M. \& Futrell, J.C. (1982). The Spiritual Exercises of St. Ignatius of Loyola: a Handbook for Directors. New York: La Jacq Publishing.

Crisóstomo, J. In Matth.

De Loyola, I. (2010). Ejercicios espirituales (Vol. 26). Linkgua.

Francisco. (2013). Evangelii Gaudium, 24 noviembre.

Francisco. (2016). Amoris laetitia, 19 marzo.

Francisco. (2019). Christus Vivit, 25 marzo.

Iparraguirre, I. \& Dalmases, C. (1963). San Ignacio de Loyola. Obras completas. Madrid: BAC.

Juan Pablo II. (1981). Familiaris consortio, 22 noviembre.

Juan Pablo II. (1988). Christifedelis laici, 30 de diciembre.

Juan Pablo II. (1992). Pastores dabo vobis, 25 marzo.

Juan Pablo II. (1993). Verititas splendor.

Lonergan, B. (2006). Método en Teología. Salamanca: Sígueme.

Martínez, J. L. (2017). Discernimiento y Moral en el Magisterio del Papa Francisco. Revista Medellín, Vol. XLIII, No. 168.

Masiá, J. (2017). Los obispos japoneses, con Amoris Laetitia, antes y después. Revista Religión.

Rahner, K. (1963). Lo dinámico en la Iglesia. Barcelona: Herder.

Rawls, J. (1977). A Theory of Justice. Cambridge, Mass: Harvard University Press.

Rojas, H. (2019). Exhortación apostólica Christus vivit: Toda vida cristiana es vocación. Mensaje, 679.

Ruíz Jurado, M. (2002). El discernimiento espiritual: teología, historia, práctica. Madrid: BAC.

Ubieta, J. A. (1967). Biblia de Jerusalén. Bruxelles: Desclée de Brouwer. 